\title{
Survey on the Career Development Course for Chinese Free Normal Education Students
}

\author{
Yan Yi, Li Yi-ming \\ Southwest University, Chongqing, China
}

\begin{abstract}
Free normal education (FNE) policy benefits not only students, but also provinces which lack high quality teachers. Although this policy asks the students who join the program to get the teacher job back to the provinces where they come from, the students still face the situation of job-hunting and career planning. So, the Career Development Course (CDC) is necessary to them. We conduct a survey to acknowledge the current situation of the CDC for FNE students and find out a series of problems: 1 . The subject is narrow; 2 . The practical curriculum resources are short; 3. The pertinence is imprecise; 4. The teaching method is monotonous; and 5. Students' subjective initiative is low. There are three ways to solve these problems and to improve the effectiveness of the CDC for FNE students: (a) implementing the whole process CDC; (b) integrating modules of curriculum resources; and (c) strengthening the pertinence of the curriculum content.
\end{abstract}

Keywords: free normal education (FNE), Career Development Course (CDC), survey problems, recommendations

\section{Introduction}

The China State Council put forward the free normal education (FNE) policy (for trial implementation) in 2007, and it has been implemented in six normal subordinates universities that directly governed under the Ministry of Education. This policy not only exempts all the tuition of students during university years, but also provides a fixed monthly living allowance, under a condition that requires students only to get a teacher job at the provinces where they from and to engage in primary and secondary schools for at least 10 years after graduation. This policy is designed to provide students with a job security commitment as well as to supply the less development areas enough new teachers who get high quality normal education. Although the employment policy has many advantages, it limits normal students in choosing regions and industries objectively. Besides, it has some negative influences on students' learning, initiative, and enthusiasm of career choosing. All of these require educators to initiate the Career Development Course (CNC) to help normal education students gain the skills and active attitude of teacher job-hunting. Moreover, the course helps students plan and develop their whole career.

From the current research, studies of the CDC focus on how to implement effective employment guidance and career education in colleges and universities. Reform of the CDC is the theme of these studies, such as arranging whole course teaching, compiling scientific textbook, verifying teaching forms, specializing teachers, improving teaching institutions, standardizing teaching management, advancing academic study, and so on. The

Yan Yi, Ed.D. candidate, Faculty of Education; Institute of Marxism, Southwest University.

Li Yi-ming, Ph.D., lecturer, Institute of Marxism, Southwest University. 
representative viewpoint of "big course and small teaching" referred by Shi and Wu (2007) implies that the CDC should set diverse content and limit teachers' lecture. Sun and Liu (2010) reanalyzed guidance for the whole of vocational college students and refered to the conception of "whole process of career guidance", which means starting the CDC at the very first time that students step into college and sustaining the course during the whole period of their college times. According to the career guidance theory of two-way choice and job matching, the "whole process", which implies “all grades and gradual phases”, implements with all kinds of courses as employment guidance course, expert report, employment service information network, professional orientation testing, etc.. The "whole process of career guidance" designs a teaching plan package to help students recognize and understand themselves (their interests, capabilities, and talent), set up professional respective, correct career choosing idea, cultivate their professional quality as soon as possible, and cultivate their ability to make job forecasting and decision with information. On the curriculum models, Zhou (2005) put forward a teaching model called "three levels, whole process"; Zhou (2006) proposed a designed whole process employment guidance system based on Web for college students; Zhou and Zou (2007) put forward the operation mode of the four modernization respectively based on the connotation "full process, whole-staff-participation, specialization, and informalization" (hereinafter referred to as the "four modernization”); and Sun (2010) proposed the guiding mode: whole course, whole-staff-participation, three-dimensional, and so on.

Although there are many existing studies in this field, studies focusing on the CDC for FNE students are rare, especially the studies of the current status. In view of this phenomenon, this study will have a series of survey on the CDC for FNE students in order to find the problems in the course and come up with the corresponding solution strategies.

\section{Method}

\section{Respondents}

Southwest University is one of the six normal universities that directly governed under the Ministry of Education and also run the FND policy. It has the largest number of free normal students who are most widely covered the provinces and cities across the country. The survey selected 3,000 4th grade students from 31 colleges as objects. The data gained are representative and extensive. The randomly selected students of the survey already have been taught the CDC.

Because there is only one request for selecting the participants, i.e., they must on campus, so if we ignore the extreme situation (although schools do not use the random manner in providing objects), we can also imply that the participanting students sample provided by those schools who do not know our survey intention is close to random.

\section{Data Collection}

The questionnaire design is given priority to enclosed choice, open questions are complementary. The questionnaire is divided into the following aspects: three topics and 10 sections which are teaching content (establishing a career and career awareness, career development planning, improving the employment ability, job-searching process guidance, vocational adjustment and development, and entrepreneurship education), teaching arrangement (start time, the number of classes, teaching methods, etc.), suggestions about the CDC, etc.. 
The questionnaire has been carried out on campus. A total of 3,000 questionnaires had been given out and 2,758 recycled, which include 2,492 valid simples. The recovery rate is $90.36 \%$ and the effective rate is $90.36 \%$. Therefore, this questionnaire survey is valid.

We mainly use text documents for data entry and summary, meanwhile, we use the Statistical Package for the Social Sciences (SPSS) for statistical analysis. We also use methods of description and chart in analysis.

\section{Survey on the Current Situation of the CDC for FND Students}

\section{Survey on Student Interest and Gains of CDC}

Student interest of CDC. As shown in Table 1, 66.13\% of the students expressed their interest in the CDC, 28.44\% said their interest was general, and only 5.43\% expressed that they had no interest. We can see that most FNE students can recognize the significance of the CDC clearly and have interest in accepting the guidance.

Table 1

Students' Interest Degree to the CDC

\begin{tabular}{lllll}
\hline & Very interested & Interested & General & Not interested \\
\hline Percentage (\%) & 15.72 & 50.41 & 28.44 & 5.43 \\
\hline
\end{tabular}

Interest and gains to all sections of CDC. In premise of the majority normal students having interest in the CDC, we have further studied on the degree of interest and gains to the CDC content. Results are shown in Table 2. The students are most interested in course section of "improving the employment ability" (24.36\%), following by "guidance in the job-searching process" (19.99\%), "career development planning" (17.29\%), "the establishment of career and career awareness" (14.84\%), and "vocational adjustment and development" (13.74\%). The students gain most in the section of "guidance in the job-searching process" (23.4\%), following by "improving the employment ability” (19.8\%), “career development planning” (18.9\%), "the establishment of career and career awareness” (18.5\%), and “vocational adjustment and development” (13.6\%).

Table 2

Interest and Gains to All Sections of the CDC

\begin{tabular}{lll}
\hline Course section & Most interested in (\%) & Gains after class (\%) \\
\hline Improving the employment ability & 24.36 & 19.8 \\
Guidance in the job-searching process & 19.99 & 23.4 \\
Career development planning & 17.29 & 18.9 \\
The establishment of career and career awareness & 14.84 & 18.5 \\
Vocational adjustment and development & 13.74 & 13.6 \\
\hline
\end{tabular}

\section{Survey on Career Establishment and Awareness}

Self career planning. College students should establish self-awareness of career development and professional concepts, and have the will to make positive efforts for self career development. According to the study, $7.77 \%$ of the students have already made the career planning carefully among the 2,492 participants; 73.06\% only made a simple plan; $14.56 \%$ do not know how to plan it; and $4.61 \%$ students have never planned (see Table 3). According to the result of this survey, we can draw the conclusion that the students have a certain sense of making career planning, but only few of them have scientific planning and most of them have made a plan in a hazy state. 
Table 3

Self Career Planning

\begin{tabular}{lc}
\hline Status & Percentage (\%) \\
\hline Plan career carefully & 7.77 \\
Made a simple plan & 73.06 \\
Do not know how to plan & 14.56 \\
Have never planned & 4.61 \\
\hline
\end{tabular}

Career planning time. As shown in Table 4, 83.7\% of the students have engaged in the planning before the junior year: $18.9 \%$ of freshman fulfilled a career plan; $34.4 \%$ fulfilled a plan by the sophomore year; and $30.4 \%$ fulfilled by the junior year. Only $4 \%$ of the students come to make a career plan in the senior year, and $12.3 \%$ of them have never made a career plan.

Table 4

Career Planning Time

\begin{tabular}{ll}
\hline Time & Percentage (\%) \\
\hline Freshman & 18.9 \\
Sophomore & 34.4 \\
Junior & 30.4 \\
Senior & 4.0 \\
Random & 12.3 \\
\hline
\end{tabular}

Clarity of career development goals. As shown in Table 5, 34.61\% of the students have moderate career development goals, and $37.83 \%$ have clear career development goals. From the overall, the clarity level of the goals is above the average level $3.45(S D=0.947)$.

Table 5

Clarity of Career Development Goals

\begin{tabular}{llllll}
\hline & Very clear & Clear & Moderate & Not clear & Have no idea \\
\hline Percentage (\%) & 12.91 & 37.83 & 34.61 & 10.91 & 3.75 \\
\hline
\end{tabular}

\section{Survey on Career Development Planning}

Career planning enables students to understand themselves, to acknowledge the occupation, to adapt to the environment, to learn career development decision-making, to form the preliminary career arrangement, and to identify career goals at different stages of life.

So, we have surveyed the current situation of students' self-understanding and their understanding of occupation and environment in order to provide data for supporting and guiding the course reform in this section.

Understanding yourself. To choose and plan a successful career, students must have a accurate self-assessment and understanding of their own vocational interest, ability, and personality. All of these help students select the most suitable development path for their life-time career. As shown in Table 6, the rank of students' self-knowledge is as follows: Values (3.74) > Personality (3.66) > Interest (3.55) > Capabilities and skills (3.44). In short, FNE students have a clear self-awareness, but they need to raise the awareness of ability and skills. If students cannot make clear what are their own strong capabilities and talent, they will misjudge their career vision. So, the CDC should strengthen abilities and skills training. 
Table 6

Understanding Yourself (Class 1-5)

\begin{tabular}{lllll}
\hline & Values & Personality & Interest & Capabilities and skills \\
\hline Degree & 3.74 & 3.66 & 3.55 & 3.44 \\
\hline
\end{tabular}

Understanding of occupation and environment. The method of collecting and managing the information about occupations and industries that students will engage into after graduation is the foundation of a successful career. As shown in Table 7, the students have rather vague understanding of the targeted career, especially at the respect of employment policy which they eagerly need to know more diverse relevant ones. Knowledgeable levels of other aspects are as follows: Personal qualities (3.44) > Generic skills (3.23) > Professional skills (3.21) > Employment policies (2.88).

Table 7

Understanding of Occupation and Environment (Class 1-5)

\begin{tabular}{lllll}
\hline & Personal qualities & Generic skills & Professional skills & Employment policies \\
\hline Degree & 3.44 & 3.23 & 3.21 & 2.88 \\
\hline
\end{tabular}

Survey on Job-Hunting Process Training in the CDC

Degree of information collecting ways. Finding a satisfactory job not only depends on a person's knowledge, ability, social factors, and economic factors, but also the way of information collecting and processing. Therefore, the employment information has a pivotal position in the process of employment. As shown in Table 8, the ways students master relatively well are "information provided and recommendations by school (including campus recruitment)" (3.14) and "social practice or internship" (3.12), while the average degree in "government employment guidance services", "advisor recommended", and "job agency" is almost 2.6, which means that the students seize these ways poorly.

Table 8

Degree of Information Collecting Ways (Class 1-5)

\begin{tabular}{ll}
\hline Ways of job information collecting & Class \\
\hline Information provided and recommendations by school (including campus recruitment) & 3.14 \\
Social practice or internship & 3.12 \\
Mass media (e.g., television, papers, magazine, and Internet) & 3.04 \\
Family or personal social-relations & 2.97 \\
Investigating the job place & 2.85 \\
Social recruitment & 2.83 \\
Government employment guidance services & 2.77 \\
Advisor recommended & 2.62 \\
Job agency & 2.53 \\
\hline
\end{tabular}

Degree of job-searching ability. As shown in Table 9, the rank of degree in finding employment is as follows: Etiquette (3.16) > Resume making (3.07) > Interview tips (2.94). We should enhance the guidance in the section of interview tips for students.

Relevant knowledge of employment rights and interests. As shown in Table 10, FNE students have poor understanding of the employment rights. The master level is below average. All aspects conveyed are lower than 3 , which showed that the students rarely know the relevant laws. 
Table 9

Degree of Job-Searching Ability (Class 1-5)

\begin{tabular}{llll}
\hline & Etiquette & Resume making & Interview tips \\
\hline Class & 3.16 & 3.07 & 2.94 \\
\hline
\end{tabular}

Table 10

Knowledge of Employment Rights and Interests (Class 1-5)

\begin{tabular}{lllll}
\hline Content & Social insurance & $\begin{array}{l}\text { Employment agreement with } \\
\text { the labor contract }\end{array}$ & $\begin{array}{l}\text { Liability for breach of contract } \\
\text { and labor dispute }\end{array}$ & $\begin{array}{l}\text { To apply for a job in the } \\
\text { process of common } \\
\text { infringement violations }\end{array}$ \\
\hline Class & 2.77 & 2.77 & 2.70 & 2.66 \\
\hline
\end{tabular}

\section{Survey on Course Arrangement}

Time arrangement on "whole segmented course". As shown in Table 11, 59.21\% of the students think the course about career planning should be taught in freshman year; $58.08 \%$ of the students think the course about job-hunting guidance should be taught in their junior year.

Table 11

Time Arrangement on "Whole Segmented Course"

\begin{tabular}{lclcc}
\hline & Freshman & Sophomore & Junior & Senior \\
\hline Career planning & $59.21 \%$ & $29.93 \%$ & $7.75 \%$ & $3.11 \%$ \\
Job-hunting guidance & $7.47 \%$ & $23.78 \%$ & $58.08 \%$ & $10.67 \%$ \\
\hline
\end{tabular}

Teacher arrangement. The rank of students' expectations to the type of teachers is shown in Table 12: Full-time teachers in employment guidance center (30.53\%) > Human resources manager and psychology experts (29.64\%) > The occupation mentor (23.24\%) > Alumni (8.68\%) > Counselor (5.94\%). It shows that the construction of teachers' team should be strengthened on edge.

Table 12

Expectation for Different Types of Teachers

\begin{tabular}{ll}
\hline Expectation to teacher & Percentage (\%) \\
\hline Full-time teachers in employment guidance center & 30.53 \\
Human resources manager and psychology experts & 29.64 \\
The occupation mentor & 23.24 \\
Alumni & 8.68 \\
Counselor & 5.94 \\
\hline
\end{tabular}

Students' satisfaction to the course content. As shown in Table 13, students' satisfaction degree to the content of career guidance is in the middle level, and we should pay attention to that the satisfaction degree of practicality is only 3.12. Therefore, we should improve practical training in the later teaching and make students learn and grow in the teaching and practical process.

Table 13

Students' Satisfaction to the Course Content (Class 1-5)

\begin{tabular}{llll}
\hline & Timeliness & Practicality & Policy \\
\hline Class & 3.22 & 3.12 & 3.28 \\
\hline
\end{tabular}


Class size. As shown in Table 14, the class size suited by most students is less than 30 people and 30-60 is also acceptable.

Table 14

Expectation of Class Size

\begin{tabular}{llllll}
\hline & $<30$ & $30-60$ & $60-90$ & $90-120$ & $>120$ \\
\hline Percentage (\%) & 50.24 & 33.64 & 9.49 & 3.54 & 3.09 \\
\hline
\end{tabular}

Teaching methods. For the following five sections of the CDC content, FNE students rank the teaching methods they wish their teacher to use (see Table 15). We got the conclusion that different content of CDC is wished to adopt different teaching methods. It contributes directly to the construction of FNE studentship form.

Table 15

Teaching Methods for the Course Content

\begin{tabular}{lccccc}
\hline & \multicolumn{1}{c}{ Establish career awareness } & Career planning & Job-hunting ability & Interview & Career development \\
\hline Lecturing & $29.9 \%$ & $15.9 \%$ & $9.7 \%$ & $8.3 \%$ & $12.4 \%$ \\
Case study & $17.4 \%$ & $23.8 \%$ & $19.1 \%$ & $16.2 \%$ & $17.9 \%$ \\
Group study & $10.0 \%$ & $15.7 \%$ & $14.3 \%$ & $7.6 \%$ & $12.0 \%$ \\
Seminar & $18.6 \%$ & $16.7 \%$ & $15.0 \%$ & $14.0 \%$ & $15.2 \%$ \\
Consultation & $6.2 \%$ & $12.3 \%$ & $11.2 \%$ & $13.9 \%$ & $14.7 \%$ \\
\hline
\end{tabular}

\section{Current Problems in CDC for FNE Students From the Survey}

\section{The Subject of the CDC Is Narrow}

In general, the CDC is set up before graduates leaving school, usually at the graduate year. It obviously shows that it is too late, temporary, and lacking of systematic and constancy for CDC, which cause the theme of the CDC into a one-side way of interview training. The course content narrows down to job selection and interview skills, which mislead students to pay too much attention to job interview and self-packing, but ignore the really important things, such as capability exploring, problem analyzing and solving, ability of practicing, and so on. Furthermore, the essential elements for career building of student as tendency of occupation, career planning, self-awareness, and self-improvement are missing in the CDC and difficult to achieve actual effect.

\section{The Practical Curriculum Resources Are Short}

Current CDC inclines more to specialized, systematic, and theoretical teaching, while the complementary and supportive curriculum resources for the CDC are not fully utilized. For example, every college has professional expectation development lessons and employment counselors for their students. There are also outward bounds relevant to occupation development and ability-improving held by each unit. These curriculum resources usually appear in all kinds of activities in the following forms: entrepreneurship contest, the expanding of ability, lecture competition, etc., which are more targeted, practical, and enlightened. Neglecting the joint of these resources in the current curriculum causes practice separating from curriculum theory. The content of the CDC is too theoretical, lacking of practical activities, thus, reducing the effectiveness in curriculum.

\section{The Pertinence of the CDC Is Imprecise}

FNE students' career selection and development have its own uniqueness. But, the current course has not 
taken enough care of these uniqueness and lacks of pertinence in curriculum design. Firstly, the course lacks of professional guidance in normal education, such as particularity of teaching occupation, characteristics of teaching work, teacher professional development direction and methods, and so on. Secondly, the interior vocational guidance of professional should be further refined. For example, it should be differed that the employment guidance for primary and secondary school teachers, or for arts and science teachers. Thirdly, large class scale leads to the lack of personalized guidance for individual students. According to the survey, more than half of the students thought that class size should be under 30 people, and only few students thought that class size could be over 90 people.

\section{The Teaching Method Is Monotonous}

Wang (2008) has investigated on the topic of "Overall Assessment of the Current Employment Guidance Courses". The results showed that "Very dissatisfied" accounts for $41.89 \%$; "Dissatisfied" accounts for 32.77\%; "Satisfied" accounts for 22.64\%; and "Satisfied" and "Very satisfied" accounts for only $1.35 \%$. According to the survey of this study, students have strong interest in the employment tutorial lesson, but their satisfaction of it is not high. The current employment tutorial lesson still stays in indoctrinating, which lacks of interaction experience in the class and the curriculum content concentrates on single skills for employment theory. The modern teaching models of diversification, informatization, and systematization are not formed.

\section{The Subjective Initiative of Students Is Low}

In general, the CDC is set up in the junior or senior years. Unfortunately, this period lags behind the optimal time for students' career planning and tendency of vocational selection. They can only put energy into some remedial content, like cramming employment policy, collecting job information, training interview skills, experiencing simulated interview, etc., which are shortsighted and with low efficiency, even to be invalid. Students with low efficiency means that they have less subjective initiative and negative attitude, which appears in three kinds of ways: 1 . Students learn without concentration and there is no interaction between the students and the class teacher; 2 . Students show randomness to the homework and practical requirements; and 3. Students play truant or abstain from school directly.

\section{Conclusion}

According to the survey, it is not difficult to find that the CDC for FNE students at China normal universities now is in a nice hobble. On one hand, more and more requests have be asked to the CDC form students, universities, and employers. On the other hand, the current curriculum setting, teaching methods, and other course elements of the CDC are failed to meet those demands. Unlike other specialized curricula, although the CDC also has its own characters as an independent course, but it is much easier affected by the factors out of curriculum itself, like employment policy or ecomomic situation. This means that slight changes can not slove all those problems of current CDC we find from the survey above. Things we need to do to develop the CDC is reconstruct the course as a whole poject.

\section{Recommendations}

\section{Implementing the Whole Process CDC}

"The whole process" is built the CDC as a whole-aspect course including time, phase, specialty, and content. As regards time, it means that running the course from the very beginning of the college time of 
students to their graduation. As regards phase, it means that the course would be carried out by stages gradually according to the learning, living, psychological characteristics, and needs of different grade students. As regards specialty, it means that the course for different specialty should adapt its own characteristics. And as regards content, it means that the course should include career planning, vocational education, vocational tendency evaluation, professional skills training, innovation education, training of the pioneering consciousness and ability to business establishing, employment policy guidance, employment concept education, employment skills training, employment information service, etc.. In order to maximize the effectiveness of the course and promote students' career planning ability, concept of “whole process” pays attention to arranging the CDC in stages while integrating different educational and teaching resources that ask for whole-staff-participation.

\section{Integrating Modules of Curriculum Resources}

Integrating modules of curriculum resources means that organizing all relative curriculum resources that are effective for knowledge gaining or skills training around a certain theme. The student curriculum resource should not be only limited to the content of curriculum itself, but also be fully integrated with resources, like faculties and student associations, campus network, information network, and others in order to provide a full range of services for students. These resources each has its own characteristics: departments mainly focus on the professional development and employment guidance of professional field; student associations emphasize on the practice and other ways to promote students' skills; and the network resources are a powerful information network which has rich resources that can provide students with employment information.

"Curriculum resources modular" designing can change the inherent defects of the traditional course curriculum designing, and construct a kind of curriculum structure with independent choice, flexible organization, and openness and independence. It combines "teaching", the center of theoretical teaching in traditional courses, and "learning", the center of the extended curriculum resources, showing students the process of occurrence, development, and formation of knowledge during the development of vocational abilities and job choice, helping students acquire the career planning on job attitudes, skills, and knowledge, making the content easier to operate, and being conductive to the students to combine theory study and practice activities.

\section{Strengthening the Pertinence of Curriculum Content}

According to the particularity of the vocational development and employment of the FNE students, with applying of whole process course and integrating module of curriculum resources, the content selecting should match the teaching profession that FNE students study on, which include four dimensions: 1. For the development needs of students in different periods, a different modular concept course should be provided; 2 . Teaching methods for students should flexible according to the characteristics of different professional development in different fields; 3. Different professional guidance should be provided for different professional development requirements; and 4. Personalized guidance should be provided for different individuals.

\section{References}

Shi, Y. C., \& Wu, X. B. (2007). Considerations on enhancing the construction of employment guidance course for college students. Education Exploration, 4, 112-113. (In Chinese)

Sun, B., \& Liu, D. G. (2010). Explorations on the whole process development of employment guidance for higher vocational college students. China Electronic Power Education, 13, 174-175. (In Chinese) 
Sun, Y. X. (2010). Investigations on constructing whole process, whole staff participating and stereoscopic employment guidance model in universities. China Collective Economy, 8, 178-179. (In Chinese)

Wang, Y. (2008). Survey: Whether the course of employment guidance is helpful or not. China University Students Career Guide, 20, 32-34. (In Chinese)

$\mathrm{Xu}, \mathrm{X}$. Y. (2008). On current situations and methods for improvement in teaching of employment guidance in universities. Journal of Liaoning Educational Administration Institute, 12, 7-8. (In Chinese)

Zhou, B. (2008). University of "situation and policy" "curriculum model” design paradigm study. Inheritance, 3, 52-53. (In Chinese)

Zhou, P. S., \& Zou, X. R. (2007). The high school employment guidance “four modernizations” operating model design. Journal of South-Central University for Nationalities (Social Science Edition), 7, 178-182. (In Chinese)

Zhou, Y. Q. (2005). Applications and considerations on the "three levels, whole process" teaching model. Journal of Hebei Radio \& TV University, 3, 48-50. (In Chinese)

Zhou, Z. (2006). Design and realization of the whole process employment guidance for college students based on Web. Journal of ICT in Education, 9, 42-43. (In Chinese) 